\title{
The Development of Transferable Skills in a Variety of Economics Courses
}

\author{
John Deal (corresponding author) \\ Dept. of Economics, Manchester University \\ 604 E. College Ave., North Manchester, IN. 46962, United States \\ Tel: 1-260-982-5301_E-mail: jldeal@manchester.edu \\ S. Aaron Hegde \\ Dept. of Economics, California State University - Bakersfield \\ 9001 Stockdale Ave., BDC, Bakersfield, CA. 93311, United States \\ Tel: 1-661-654-2495 E-mail: shegde@csub.edu
}

Received: August 4, 2015 Accepted: August 30, 2015 Published: September 16, 2014

doi:10.5296/ire.v3i2.8098 URL: http://dx.doi.org/10.5296/ire.v3i2.8098

\begin{abstract}
Surveys of business leaders indicate that they believe colleges generally do a poor job of developing transferable skills (e.g., writing, critical and analytical thinking) in their graduates. Economics instructors often attempt to convey these skills as a secondary benefit of content delivery and efforts to get students to 'think like an economist'. We argue that the of the skills that transfer across disciplines and into the job market should be more purposeful, particularly since most students take only one or two economics classes in college. In this we present two examples of projects - an integrated data/writing project for a Principles of Microeconomics class and a real-world simulation project for an Agricultural Finance class designed to help students develop skills that transfer across classes and into the job market. These projects are designed to build skills in a sequential and integrated manner (i.e., scaffolding), giving students an opportunity to build upon and practice previously developed skills. We provide a description of each project and a brief review of the outcomes and issues (e.g., benefits and limitations) of each project. Our initial experiences would indicate that students perceive value from the approach of placing explicit emphasis on the development transferable skills.
\end{abstract}


Keywords: Transferable skills, Integrated data/writing project, Simulation project

\section{Introduction}

Surveys of business leaders often find that they believe recent college graduates are not prepared to enter the workforce. In particular, they express concerns over the perceived failure of colleges to teach transferable skills (also known as generic or core skills). Although there is some disagreement as to the meaning of transferable skills, we define these skills as ones that are not discipline specific and that transfer across courses, in addition to being applicable to the specific requirements of a job. These transferable skills include effective writing, analytical reasoning, data management and analysis, and critical thinking. Business leaders also argue that schools fail to supplement discipline knowledge with opportunities to apply that content knowledge to real-world problems. A 2011 survey conducted for the Accrediting Council for Independent Colleges and Schools found that only seven percent of employers believe that post-secondary institutions do an "excellent" job preparing students for the workplace, while almost forty percent of employers feel like they do a 'fair or poor job' (ACICS, 2011). Although the types of skills desired by businesses vary in importance across different surveys, most indications are that communication skills and analytical skills usually rank at the top of the list (English et al., 2012). In addition to prodding from business leaders, institutions of higher education have been charged by governments in many countries (e.g., Australia and England) to place a greater emphasis on the development of generic skills to maintain funding and accreditation (Badcock et al., 2010; Clark, 2011).

Although governments, accrediting agencies, and businesses encourage institutions of higher education to place a greater emphasis on transferable skills, these calls have often been met with resistance or ineffective implementation. While some academics are opposed to teaching for 'employability' purposes, Barrie (2006) argues that this reluctance or failure is often due to a disagreement in academia concerning how these transferable skills are learned and the nature of the relationship between discipline knowledge and the development of those skills. He argues that academics view transferable skills in four distinct ways - (1) precursors, (2) complements, (3) translators, or (4) enablers. Generic skills as precursors precede university training and are only relevant if remedial training is needed, while skills as complements are seen as independent from discipline content, though worthwhile outcomes by themselves. Generic skills that are translators transform discipline knowledge into practical applications, while enabling skills are seen as "abilities that infuse and enable all scholarly learning" and "provides both form and function to disciplinary knowledge" (Barrie, 2006, p. 289). Regardless of the view of the role or the nature of generic skills, educators who fail to make the delivery of generic skills explicit may not make students aware of their attainment and therefore unable to apply them to problems outside the discipline content used to implicitly deliver the skills (Saunders, 2011).

Although preparation of students for the workforce should not be the sole purpose of a college education, it would be irresponsible for educators to ignore the perceived disconnect between the education being provided and the skills being demanded in the workplace. Most students take one or two economics courses, mostly to fulfill general education or business 
requirements. Siegfried and Watts (2014) estimate that only about $40 \%$ of undergraduates take an economics course, and only about $1.7 \%$ of undergraduates become economics majors. As a result, an opportunity to provide added value to the large number of students who get limited exposure to economics is lost. Teachers in the discipline generally place an emphasis on using content to teach students to 'think like an economist'. Siegfried et al. (1991) define thinking like an economist as "...using chains of deductive reasoning in conjunction with simplified models (such as supply and demand, benefit-cost analysis, and comparative advantage) to illuminate economic phenomena" (p 21). The economics discipline usually equates generic skills, particularly critical thinking, with problem solving skills associated with the application of economic models and tools to theoretical or real-world situations. Other transferable skills (e.g., writing) are often seen as useful skills that compete for limited instruction time with disciplinary knowledge and are therefore given less emphasis (Jones, 2009).

While many disciplines, primarily in the natural sciences, have long provided students with active learning (e.g, laboratory) and writing (e.g, lab report) experiences that help develop transferable skills, the economics discipline has often relied on a lecture and discussion-based format (i.e., "chalk and talk") and has been slow to adopt new pedagogical changes in education. The continued urgings of a number of economists, such as David Colander, William Becker, Michael Watts, and Kim Marie McGoldrick, to address pedagogical shortcomings in the teaching of economics has begun to gain some traction in the discipline. For example, a quick review of the Journal of Economic Education demonstrates the wide variety of teaching innovations currently being used in the classroom, including classroom experiments, writing assignments, and the use of media to convey economic concepts (Blackwell, 2011; Simpson \& Carroll, 1999; Considine, 2006; Watts \& Christopher, 2012). These approaches are often centered on the conveyance of content, while placing less explicit focus on the development of transferable skills.

McGoldrick and Garnett (2013) recently argued that teachers should "encourage [students] to move beyond algorithmic application of textbook principles" and engage in more "big think" questions. They demonstrated this with a differential tuition pricing module that is conducted in multiple stages (i.e., scaffolding). Green, Bean, and Peterson (2013) presented an example of a scaffolding assignment for an intermediate microeconomics class that required students to go beyond the typical algebraic homework problems by connecting the content to real-world issues (the use of parking meter fees) contained in media. In addition, they required students to develop a 'recommendation memo' to use the data analyzed by the students in the earlier segments of the project. In both of these cases, the authors argued for a sequential learning project that attempted to get students to build a stronger understanding of the content, in addition to developing other skills (e.g. writing).

The approach to transferable skills presented in this paper combines the complement and translator views of these skills outlined in Barrie (2006). While the development of transferable skills can be taught without reference to specific disciplinary content, a connection to the disciplinary content can both strengthen those skills while allowing the student to better understand and be able to apply the content. We argue that the development 
of transferable skills should be more purposeful and not secondary to content. This paper presents a couple of approaches designed to obtain this outcome - an integrated data/writing project designed for a Principles of Microeconomics course and a real-world simulation designed for an Agricultural Finance course. These projects are designed to develop transferable skills, while at the same time strengthen the students' understanding and retention of course content.

The remainder of this paper is organized as follows. The next section describes an integrated data/writing project that could be implemented in a Principles of Microeconomics course, but could also be employed in a number of other economics courses. The following section describes the implementation of a simulation approach to teach risk management in an Agricultural Finance course. The final section provides concluding comments and arguments for more intentionally integrating the development of transferable skills along with the delivery of content.

\section{Integrated Data/Writing Project}

Although businesses value many skills, including oral communication and teamwork, two skills that are often cited as essential are written communications and the ability to collect, manage, and analyze data (ACICS, 2011). At the same time, those skills are generally transferable across a variety of college courses. Economics courses at the introductory level are designed to introduce students to a variety of content and rudimentary modeling approaches. In a nutshell, the goal is to get students to begin 'thinking like an economist'. An increasing amount of effort has been devoted to improving teaching pedagogy (i.e., moving from a "chalk and talk" approach to more interactive learning) in economics in the last few years, but less emphasis has been placed on the development of skills that could potentially complement the mastery of content.

Over many years of teaching, the authors have become convinced that content and development of skills are both substitutes and complements. To be able to concentrate on the development of skills, it is necessary to sacrifice some content, but integrating content with the development of skills can help enhance comprehension and retention of the remaining content. Efforts to more explicitly introduce development of writing and data skills into introductory classes could be met with mixed results if the data and writing components are separate. Students could feel that the projects are disconnected with the content of the course if the connection is not made clear to them. The failure to connect assignments, both with each other and the content of the course, gives students the impression that the projects are 'busy work'.

\subsection{Project Description}

This project (see Appendix 1) integrates the data and writing components with each other and with the content in the course and has the following components: (i) pre-project data norming: (ii) project data analysis; (iii) article summary and analysis; and (iv) position paper.

Pre-project data norming: Since students in an introductory class have had varying levels of exposure to data analysis, an assignment was provided to introduce them to basic concepts 
and tools (e.g., choosing the 'best' graphical format to present different types of data, distinguishing between negative and positive correlation) before assigning the integrated project. In addition to providing students with some experience handling data before the introduction of an integrated project, this assignment allowed the coverage of concepts that did not easily fit with the chosen project topic that tied together the various components of the integrated project. For example, students were given various types of data (e.g., the percentage of the population which is Hispanic and the percentage of households below the poverty line in each of the 254 counties in Texas) and asked to determine which type of graph (a scatterplot in this example) would be most appropriate to use when trying to demonstrate the relationship between the variables.

Project data analysis: In our introductory microeconomics class, a significant amount of class time was spent on labor markets and income distribution issues, so connecting the project to the course was easy. If another instructor wanted to emphasize different materials (for example, the environment or business pricing decisions), it would be easy to adapt the project to connect with that material. In the income inequality project, students were required to find United States time-series data on income inequality, plot the data, calculate descriptive statistics, and provide a brief written analysis of the trends. In addition, students were asked to find cross-country income inequality data, determine which countries had the highest and lowest levels of income inequality, and research the country to determine possible causes for the differences. The Gini coefficient was chosen as the measure of income inequality because it is readily available and easily understood, but the project could be extended by having students compare more than one measure of income inequality (e.g., quintile distribution). The data analysis component of the project exposed students to skills (e.g., entering data in a spreadsheet, plotting the data) that could be transferred to other courses, but could also deepen their understanding of how income inequality is measured and the degree of variation in data over time and across geographic space.

Project article summary and analysis: While students in an introductory class are generally not prepared to read peer-reviewed economics journals, there are many mainstream publications (e.g., The Economist, The Wall Street Journal) that contain a discussion of a variety of economic issues. For this project, students had to summarize and analyze the New York Times article "A Relentless Widening of Disparity in Wealth" by Eduardo Porter. The analysis component of the project required students to evaluate the quality of Porter's arguments and evaluate the validity of the evidence he presented to support his claims.

Project position paper: Students needed to choose and defend one of the following two positions - (1) income inequality is not a significant problem and the government should not address the issue or (2) income inequality is a significant problem and the government should enact policies to address the problem. If they chose the second option, they had to recommend potential policies to help alleviate the problem. The position paper allowed them to incorporate material on labor markets presented in class and the article summary and analysis, in addition to further refining their ability to collect and analyze data. In addition to enhancing writing skills, the position paper required students to develop an argument and provide supporting evidence. Students were required to write the paper with a general 
audience in mind, so they had to convert the economic jargon into everyday language. This process of converting the material into everyday language required students to understand the material, not just repeat concepts they failed to fully grasp.

\subsection{Project Outcomes and Issues}

One concern with incorporating the project into class would be that student performance on the content portion of class might suffer if less time was devoted to content. While an analysis controlling for student characteristics has yet to be completed, anecdotal evidence indicates that this was not been the case. Effectiveness of the project was assessed by including a control group (another principles of microeconomics class). The content covered in both classes was almost identical and students were administered a cumulative final exam in each class. The mean grade on the cumulative final exam was 73.4 in the class without the project and 79.2 in the class with the project. While it cannot be claimed that the project increased understanding of content, it may not have had a significant negative impact. If the student's understanding of content is not diminished and other transferable skills are gained, then the net benefit of the project is positive.

Although student perceptions do not provide conclusive evidence to the efficacy of the project (this could take years to monitor results), the value a student receives from an activity is tied to their perceptions of its usefulness. A survey was distributed to the treatment class to ascertain student perceptions of the value of the project, their evaluation of the project's strengths and weaknesses, and suggestions regarding possible improvements in the project. The last two components were ascertained through open-ended questions, but the first component was captured through the following questions:

On the following scale (with 1 = "not useful at all" and 10= "extremely useful"), rate the usefulness of the data projects and article summary/analysis to

The blank contained one of three questions: (i) a better understanding of the content in the course, (ii) the development of skills that will transfer into other classes, and (iii) the development of skills that will transfer into employment. The example of the integrated project in Appendix 1 contains a position paper and a combined article summary and analysis. This survey was conducted for a project that contained no position paper, but contained a separate article summary and article analysis.

Results for each of the questions are contained in Table 1 . There were 40 students in the class and there was $100 \%$ participation in the survey.

Table 1. Summary results from principles of microeconomics survey

\begin{tabular}{llllll}
\hline & Mean & Median & St. Deviation & Minimum & Maximum \\
\hline Content & 7.43 & 7.95 & 1.83 & 1 & 10 \\
Other Classes & 7.95 & 8.00 & 1.61 & 4 & 10 \\
Employment & 7.95 & 9.00 & 1.56 & 4 & 10 \\
\hline
\end{tabular}


Results of the survey indicate that students generally believed the project resulted in a better understanding of course content (a secondary goal of the project), but also helped develop skills that would be useful in their other courses and in future or current employment. In answers to the open-ended questions, students offered that they achieved a greater understanding of labor market outcomes and issues related to economic data, but their responses provided no evidence that the project indirectly contributed to content knowledge in other topics covered in the class.

There are a number of issues that should be addressed before adopting this project. First, the additional grading, particularly for those who typically do not require writing assignments, can be somewhat daunting. The projects were used in classes that ranged from thirty to forty students, so the grading was manageable. For classes in excess of forty students, particularly without a teaching assistant, alternative approaches could be employed. In earlier versions of the project, the class was divided into teams of two, so the amount of time required to grade projects was reduced by half. This does create a potential free rider issue, but this is a reasonable trade-off for the reduction in grading time. In addition, the team approach allows the students to further develop teamwork skills, another skill highly valued by employers. It is also vital that intentional connections between the project and course material be established early on.

Adequate time should be devoted to preparing students for each section of the project (e.g., providing examples of a good summary/analysis) or reviewing the completed assignments. While this does take time away from the presentation of new material, it emphasizes the importance of the project and allows students to contribute to a common learning experience. The additional use of class time may also have a tertiary benefit in that it forces the instructor to prioritize lecture material (which is often difficult, even for experienced instructors) and shifts learning back to the student.

The weight assigned to the project must reflect the amount of work required to complete the project (and the value placed on the project by the instructor); otherwise, the students feel that they are not adequately rewarded for the effort spent on the project. Unless a significant portion of the final grade (up to $30 \%$ ) is attached to the integrated project, students (rightly or wrongly) will feel that the instructor does not place a high value on the project.

\section{Simulation Project}

A report commissioned by the American Association of Colleges and Universities (AACU) titled "Falling Short? College Learning and Career Success" surveyed employers and identified the following skills as severely lacking among college graduates: (i) written and oral communication: (ii) teamwork; (iii) ethical decision-making; (iv) critical thinking; (v) ability to apply knowledge in real world settings. A majority of employers felt these skills could be learned through real world projects (AACU, 2015).

Another approach to providing these transferable skills is to use a real world simulation. Students often find risk management to be a challenging topic, which can be easier to grasp through a simulation. Studies have shown that students learn concepts quicker through 
simulations than through traditional lectures (Schute \& Glaser, 1990). Hence, a simulation was designed in an upper division economics class (agricultural finance) to teach students about the derivatives market as a risk management tool.

\subsection{Project Description}

Over a six-week period, this simulation required student groups in an agricultural finance class (upper-level economics) to play the role of corn farmers and to use the futures market to mitigate risk. Each group was given a weekly crop report, including weather information, from which to make crop-planting decisions. All provided information was based on actual historical events, though unidentifiable to students. At the beginning of each week of the simulation, groups chose a portion of their land on which to plant corn. Their choices were either low (50\% planting), medium (75\% planting) or high (100\% planting) and were based on a 'current' crop report, which included actual information from the USDA for a given year. The weekly crop report included data on corn harvest for two crop years preceding the 'current' crop year. Actual spot and futures price data from the 'current' year were used in the simulation. After groups made planting decisions, a state of nature, which determined actual yield, was chosen. The state could be either be good (high yield), average (average yield), or poor (low yield). Production costs were based on an average state of nature (average yield) and the planted acreage. At the end of each week, profits were calculated and groups were ranked. Each group was given feedback regarding the potential profits they could have earned by employing different strategies.

During the first two weeks of the simulation, each group was required to be fully hedged in the futures market. Complexity was added to the simulation during the middle two weeks when groups were allowed to pick an optimal hedge ratio, based on their understanding of optimal hedge ratios, a concept covered in class. Their choices ranged from $0 \%$ hedged (no hedge) to $100 \%$ hedged (fully hedged). A final complication was introduced during the last two weeks of the simulation. Groups could choose to participate in crop insurance, which would increase their production cost by a fraction. If the state of nature as poor, those participating in crop insurance received compensation. Groups had to submit weekly written reports explaining the reasons for choices made at each stage of the project.

\subsection{Project Outcomes and Issues}

A number of issues must be addressed before incorporating this project. Similar to the integrative data project, the simulation project requires additional preparation on the part of the instructor. Weekly calculations of the student group decisions require additional time, which can be minimized by using excel (template provided in Appendix 2). Compiling weekly crop reports, based upon which the groups make weekly decisions, requires a marginal time investment. However, students get a better understanding of core concepts such as the derivatives market which can be difficult to grasp, through such a simulation, making the additional time investment worthwhile.

Students were asked to complete a self-reflection essay on the relevance of the simulation project. Majority of the students reflected that the project was a valuable exercise that made it easier for them to grasp the concept of risk management. This project enhanced their 
understanding of the material presented in the textbook. Many felt more prepared to enter the workforce based on this exercise. A couple of students managed to get internships on the basis of skills gained through the real world project.

In addition to teaching students a difficult concept, this simulation reinforced skills transferable to other courses, and especially to employment post-graduation. The above discussed simulation reinforces most of these skills through the following: (i) report submission (written communication); (ii) teamwork is the crucial element of this project; (iii) critical thinking is reinforced throughout the project, but especially by way of analyzing weekly crop reports; (iv) mastering the workings of futures markets gave students the ability to apply knowledge in real world settings.

\section{Conclusions}

While economics courses generally provide students with strong analytical skills, employers desire a wide variety of skills that are often de-emphasized in attempts to get students to 'think like an economist'. In particular, communication skills, teamwork, and application of theory and methods to real-world problems are often ignored (or at least not emphasized). This paper presents two approaches - an integrated data/writing assignment and a simulation project - that can be applied to a variety of economics courses. In both cases, students develop additional data and writing skills that go beyond that developed in the typical economics course.

Since few students take more than one or two economics classes, this more purposeful approach to developing these skills provides students with the necessary tools to be successful in other classes. At the same time, the integration of skill development with content delivery helps reinforce the content. If students see the connection between the content, skills, and real-world applications of both, they may be more likely to see the usefulness of economics and therefore may be more likely to take additional courses.

\section{References}

Accrediting Council for Independent Colleges and Schools. (2011). Summary of the findings from survey of hiring decision-makers. Retrieved May 29, 2015, from http://www.acics.org/events/content.aspx?id=4718

Association of American Colleges and Universities. (2015). Falling Short? College Learning and Career Success. Retrieved January 25, 2015, from https://www.aacu.org/sites/default/files/files/LEAP/2015employerstudentsurvey.pdf

Badcock, P., Pattison, P., \& Harris, K. (2010). Developing generic skills through university study: a study of arts, science and engineering in Australia. Higher Education, 60(4), 441-458. http://dx.doi.org/10.1007/s10734-010-9308-8

Barrie, S. (2006). Understanding what we mean by the generic attributes of graduates. Higher Education, 51(2), 215-241. http://dx.doi.org/101007/s10734-004-6384-7

Blackwell, C. (2011). Using a simple contest to illustrate mechanism design. Journal of Economic Education, 42(4), 375-387. http://dx.doi.org/10.1080/00220485.2011.606088 
Clark, A. (2011). Embedding transferable skills and enhancing student learning in a political science research methods module: evidence from the United Kingdom. PS: Political Science and Politics, 44(1), 135-139. http://dx.doi.org/101017/s1049096510002039

Considine, J. (2006). The Simpsons: Public choice in the tradition of Swift and Orwell. Journal of Economic Education, 217-228. http://dx.doi.org/10.3200/JECE.37.2.217-228

English, D, Manton, E., Sami, A. \& Dubey, A. (2012). A comparison of the views of college of business graduate and undergraduate students on qualities needed in the workplace. College Student Journal, Retrieved May 29, 2015, from http://www.readperiodicals.com/201206/2697702231.html

Green, G., Bean, J., \& Peterson, D. (2013). Deep learning in intermediate microeconomics: Using scaffolding assignments to teach theory and promote transfer. Journal of Economic Education, 44(2), 142-157. http://dx.doi.org/10.1080/00220485.2013.770338

Jones, A. (2009). Generic attributes as espoused theory: the importance of context. Higher Education, 58(2), 175-191. http://dx.doi.org/10.1007/s10734-008-9189-2

McGoldrick, K., \& Garnett, R. (2013). Big think: A model for critical inquiry in economics courses. Journal of Economic Education, 44(4), 389-398. http://dx.doi.org/10.1080/00220485.2013.825118

Saunders, A. (2011). Revisiting the skills agenda: a complicated geography. Journal of Geography in Higher Education, 35(4), 465-477. http://dx.doi.org/10.1080/03098265.2010.523683

Siegfried, J., Bartlett, R., Hansen, L., Kelley, A., McCloskey, D., \& Tietenberg, T. (1991). The Economics Major: Can and Should We Do Better than a B-? American Economic Review, $81(2), 20-25$.

Siegfried, J., \& Walstad, W. (2014). Undergraduate coursework in economics: A survey perspective. Journal of Economic Education, 45(2), 147-158. http://dx.doi.org/10.1080/00220485.2014.889965

Simpson, M., \& Carroll, S. (1999). Assignments for a writing-intensive economics course. Journal of Economic Education, 30(4), 402-410. http://dx.doi.org/10.1080/00220489909596097

Shute, V.J., \& Glaser, R. (1990). A Large-Scale Evaluation of an Intelligent Discovery World: Smithtown. Interactive Learning Environments, 1, 51-77. http://dx.doi.org/10.1080/1049482900010104

Watts, M., \& Christopher, C. (2012). Using art (paintings, drawings, and engravings) to teach economics. Journal of Economic Education, 43(4), 408-422. http://dx.doi.org/10.1080/00220485.2012.714317 
Appendix 1

Sample Integrated Data/Writing Project

Concerns over perceived increases in the degree of inequality, particularly with regard to income and wealth, have recently been raised by the general public and by many social scientists. In 2011, the creation of the Occupy Wall Street movement raised the issue in the daily news for many months. Recently, fast food workers have gone out on strike to obtain a higher minimum wage, and President Obama has proposed to raise the federal minimum wage from $\$ 7.25$ per hour to $\$ 10.10$ per hour. At the same time, economist Thomas Piketty has gained world-wide attention with his new book on inequality, Capital in the Twenty-First Century. The book has made it to the top of the Amazon best seller list, a feat almost unheard of for an economics book, and has gendered much controversy among economists and policymakers. Your assignment will be to explore the issue of inequality by combining data collection and analysis, an article summary and analysis, and a position paper.

\section{Section One - Data Presentation and Analysis}

There are a number of ways that you could look at inequality. You could look at differences in income inequality or wealth inequality, where income pertains to money earned from employment and wealth pertains to money from all sources (e.g., dividend payments on stocks). You could also look at changes in either measure of inequality over time within one geographic area (e.g., country) or compare measures on inequality at one point in time across a variety of geographic areas. Finally, you could look at how inequality varies depending on the characteristics of a particular group (e.g., educational attainment, gender, or race). In this section, you will be asked to collect data on income inequality, present that data in graphical form, and briefly describe your findings.

(A) One measure of income inequality is the Gini coefficient. Write a one paragraph description of the Gini coefficient. Make sure to discuss how the measure is constructed and how it is used as a measure of income inequality.

(B) Find the Gini coefficient (i.e., Gini Ratio or Gini Index) for the United States for the years 1947 through 2012. Calculate the mean value and the standard deviation for the data. Briefly define the terms "mean" and "standard deviation." Plot the data in the appropriate graph. Your goal in constructing the graph is to demonstrate the trend in income inequality over time in the United States. Be sure to label the axes of your graph and include a title for the graph.

(C) The Gini coefficient is constructed for most countries of the world from data collected by the World Bank. The data is often collected at different points in time. For example, data in Australia was last reported in 1994, while data in Indonesia was last reported in 2011. As a result, it makes it difficult to compare measures of income inequality across countries (though income inequality generally tends to change slowly). Due to this problem, I am going to ask you to find the Gini coefficient for the following countries in the year in which the data was reported.

(a) 2009 - Brazil, Cambodia, Chile, Honduras, Latvia, Philippines, Russian Federation, Slovak Republic, South Africa, Uganda, and the West Bank and Gaza. 
(b) 2010 - Argentina, Bangladesh, Belarus, India, Mexico, Nepal, Nigeria, Paraguay, Serbia, Swaziland, Turkey, Uganda, Uruguay, and Zambia.

Find the country with the most equal distribution and the least equal distribution of income in the (a) and (b) list combined. Provide a couple possible reasons that one country had the most equal distribution of income and the other country had the most unequal distribution of income during this time period. You will need to research the two countries to provide possible reasons for the low or high level of income inequality. Make sure to provide the citation of the sources that you used for your information.

(D) Use the data in Table A-1: Years of School Completed by People 25 Years and Older by Age and Sex on the Bureau of Labor Statistics website to answer this question.

1. You will need to use the data from 1964 to 2012. You will need to create a new variable called "\%_LHS" (percentage with less than high school degree) by dividing the number of students completing 1 to 3 years of high school by the total number of students. You will need to create another new variable called "\%_CDH" (percentage with college degree or higher) by dividing the number of students completing 4 years or more of college by the total number of students.

2. Use the data you created in part 1 of section D with Gini coefficient in section B of this question. Make sure to only use the Gini coefficient data from 1964 to 2012 in this question. Use the Gini coefficient as the dependent variable and the educational data as the independent variables. Construct 2 graphs - one with the Gini coefficient and "\%_LHS" and one with the Gini coefficient and "\%_CDH" - to demonstrate the relationship between income inequality and educational attainment. Is the Gini coefficient positively or negatively correlated with “\%_LHS" Explain. Is the Gini coefficient positively or negatively correlated with "\%_CDH”? Explain.

\section{Section Two - Article Summary/Analysis}

The instructor should choose an article for students to summarize and analyze. One possible example would be "A Relentless Widening of Disparity in Wealth" by Eduardo Porter in the New York Times (March 12, 2014). After reading the article, you should then compose a 2-3 page (typed, single-sided, double-spaced, 12-point font, 1" margins) summary and analysis of the main ideas contained in the article. The summary component of the paper should include the following: (1) the main thesis of the paper, (2) arguments and evidence provided to support the thesis of the paper, and (3) arguments or evidence against the thesis and the author's response to those arguments (if provided in the paper). The analysis component of the paper should address the following questions:

(1) Is the author a credible authority on the subject on which she is writing?

(2) Does the author appeal to the reader's emotions or to their critical thinking ability?

(3) Does the author provide adequate and credible evidence to support her position?

(4) Does the author refute or ignore credible evidence that would discredit her position?

The summary and analysis components should be combined in a logical sequence; you should not present them as separate parts of the paper. 


\section{Ml Macrothink}

\section{Section Three - Position Paper}

There are two basic issues that have arisen in the debate over inequality. First, is inequality a sufficient problem that public policy should be used to reduce the degree of inequality? Second, what types of policy instruments could be used to reduce inequality (assuming the answer to the first question is "yes")? You should compose a 2-3 page (typed, single-sided, double-spaced, 12-point font, 1" margins) position paper taking one of two positions - (1) income inequality is not a significant problem and the government should not address the issue or (2) income inequality is a significant problem and the government should enact policies to address the problem. If you choose option (2), you need to recommend some potential policies to help alleviate the problem. In either case, you should provide as much empirical evidence as possible to support your position. The paper should be written with a general audience in mind, therefore you should limit the economic jargon (as much as possible) and clearly explain any theories or models that you employ.

\section{Appendix 2}

Weekly Results

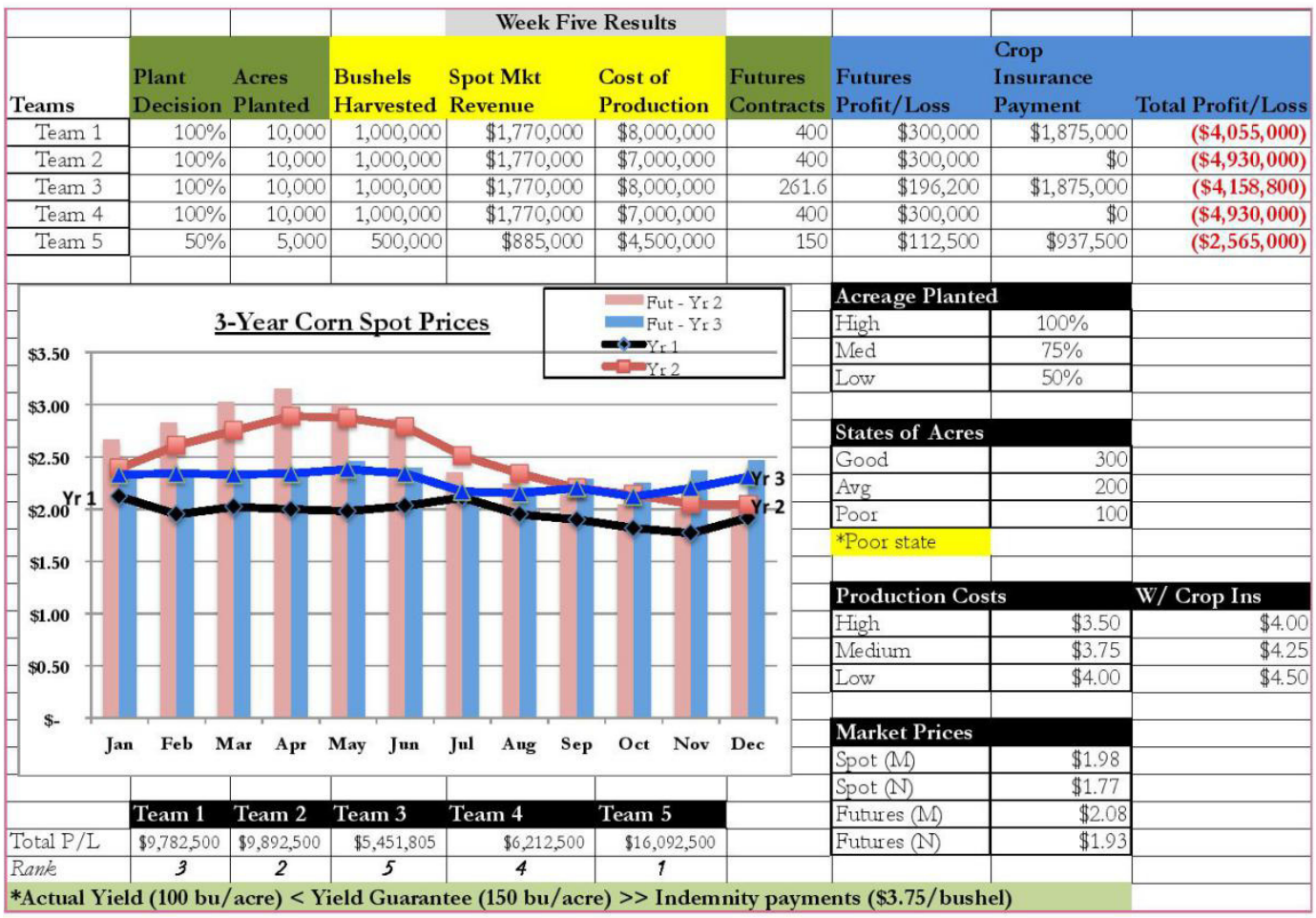

Results

\section{Copyright Disclaimer}

Copyright reserved by the authors.

This article is an open-access article distributed under the terms and conditions of the Creative Commons Attribution license (http://creativecommons.org/licenses/by/3.0/). 